\title{
Effects of diets containing Cissus rotundifolia flour on lipid profile of rats and postprandial glucose levels of normoglycemic human adults
}

\author{
Uchenna Agatha Onyechi * and Vivienne Nkiruka Ibeanu \\ Department of Home Science Nutrition and Dietetics, University of Nigeria, Nsukka, Enugu State, Nigeria.
}

Received 25 April, 2015; Accepted 17 December, 2015

\begin{abstract}
This study evaluated the effect of Cissus rotundifolia (CR), on the lipid profile of rats and postprandial blood glucose level of normoglycemic human adults. CR flour was processed using traditional Nigerian method of processing. The animal experiment involved male Sprague-Dawley rats fed for 14 days with hypercholesterolemic diet of corn oil, cholesterol, casein, mineral mix, vitamin mix, sucrose, solka floc and corn starch blended together and served as control diet (CD). The experimental diet (CRD) was CR flour added to the CD to provide $10 \mathrm{~g}$ total dietary fibre per $100 \mathrm{~g}$ but maintained similar amount of protein and fat levels as the CD. At the end of the 14 days of feeding, the rats were sacrificed and the plasma lipid levels measured. The human study involved 10 healthy subjects who fasted overnight for $12 \mathrm{~h}$. Control bread meal (CB) was two whole wheat bread rolls, apricot jam, and sufficient water. Cissus rotundifolia based bread (CRB) substituted whole wheat in the test meal. Each meal contained $75 \mathrm{~g}$ available carbohydrate (CHO). The test meal also provided $6 \mathrm{~g}$ soluble non-starch polysaccharide (SNSP). The subjects were fed the CB and CRB on two separate days. Venous blood sample was taken at fasting and postprandially for $2.5 \mathrm{~h}$ and analyzed for plasma glucose and insulin levels. Analysis of variance and repeated measure analysis of variance (ANOVA) were used to analyze the data from the animal and human experiments, respectively. The result of the rat study showed a significant $(p<0.05)$ reduction on the fasting plasma cholesterol and a reduction in the triglyceride levels of rats fed the CRD compared to the CD. The human study showed that CRB elicited a significant $(p<0.05)$ decrease in plasma glucose level and insulin at 150 and $90 \mathrm{~min}$, respectively. A significant reduction $(p<0.005)$ was found in the area under the curves (AUC) with CRB compared to the CB. It was concluded that CR could be useful in modulating blood glucose levels in humans.
\end{abstract}

Key words: Cissus rotundifolia, physiological effects, lipid, glucose, rats, human.

\section{INTRODUCTION}

There has been interest in the last decade on the potential therapeutic role of a high carbohydrate $(\mathrm{CHO})$, high fibre diet and polysaccharide gums in the dietary management of non-insulin dependent diabetes mellitus

*Corresponding author. E-mail: uche.onyechi@gmail.com. Tel: +2348066794814.

Author(s) agree that this article remains permanently open access under the terms of the Creative Commons Attribution License 4.0 International License 
(NIDDM) (Slyper, 2013). This current interest in the therapeutic dietary effect was generated from the epidemiological work of Trowell (1975). Studies (Jenkins et al., 2002; Kaczmarczyk et al., 2012; Fujii et al., 2013) have suggested a link between dietary fibre and the etiology of various chronic non-communicable diseases (NCDs). Trowell et al. (1976) noted that diabetes mellitus and certain metabolic diseases were rare in the developing countries where the population traditionally consumed diets rich in dietary fibre. However, with the advent of western civilization and adoption of a more westernized lifestyle there has been an increase in the prevalence of diabetes in developing countries (Ramachandran et al., 2012; Ram et al., 2008, Ram et al., 2004). This was related to change in dietary habits (Burkitt and Trowell, 1976; Hall et al., 2011; Jacobs, 2015), economic development and market globalization (WHO/FAO, 2003).

World Health Organization (2000) reported that 171 million people worldwide suffer from diabetes. Ramachandran et al. (2004) indicated that the greatest increase in the prevalence rate will come from the developing countries of the world like Asia and Africa. These authors postulated that there will be $42 \%$ increase in the developed countries and $170 \%$ in the developing countries. However, Guarigutata et al., (2014) reported that in 2013382 million people had diabetes; this number is expected to rise to 592 million by 2030 . These authors further revealed, that most people with diabetes live in low and middle-income countries and these will experience the greatest increase in diabetes cases over the next 22 years. Diabetes affects more than 6 million Nigerians and over 1 million are blind, out of which $80 \%$ are blind from diabetes (Uduaghan, 2002).

There are some properties of dietary fibre that are related to physiological responses and food functionality in the management of diabetes. These include water binding capacity (WBC), particle size, viscosity, soluble non-starch polysaccharide (SNSP) and nature of starch (Dreher, 1987; Brownlee, 2011; Ley et al., 2014). These properties in both human studies (Fairchild et al., 1996; Braaten et al., 1994; Brownlee, 2011; Dhingra et al., 2011) and animal studies (Johnansen et al., 1990; Ellis et al., 1996) have been shown to increase viscosity of the digesta. This is a major factor in inhibiting the rate of digestion and absorption of available carbohydrate and consequent decrease in postprandial glucose level (Ellis et al., 1996; Edward et al., 1988; Riccardi et al., 2008; Brownlee, 2011; Oputa and Chinyere, 2012).

In the South Eastern Nigeria there are numerous plant foods that are used in the preparation of vegetables soups that increase the viscosity of such soups. One such plant food is Cissus rotundifolia (CR) which is known as "ukoho" among the lbo tribe in the South Eastern Nigeria. CR is indigenous to Nigeria; it is used as viscous thickening agent, is easily available, cheap and processed in the homes for thickening vegetable soups.
C. rotundifolia is a climbing or prostrate herb. The leaves are glossy green, widely ovate to round with blunt toothed margins. This shrub is distributed in tropical and subtropical regions. CR is found throughout East Africa, Zimbabwe, Mozambique, South Africa, parts of Central Africa, Egypt and the Arabian Peninsula (FAO, 1988). The young shoots of $C R$ are used as vegetables. Their minor economic importance lies in local medicinal uses (FAO, 1988). The dried stem of $C R$ is sold as food condiment in the ground form. CR stem was harvested fresh and wet. The bark was removed by scraping. The stem was cut into small pieces and dried. The dried stem was crushed into smaller pieces and then ground in a coffee grinder (Moulinex blender/mill) into fine powder and sieved. The powered CR was a yellowish brown powder. Previous work (Onyechi et al., 2007) on the nutrient content of CR flour per $\mathrm{g} / 100 \mathrm{~g}$ dry weight showed that $\mathrm{CR}$ contained high amount of available $\mathrm{CHO}$ $(56 \mathrm{~g} / 100 \mathrm{~g})$ and high available energy of $257 \mathrm{~g} / 100 \mathrm{~g}$. The protein content was low $(4.9 \mathrm{~g} / 100 \mathrm{~g})$ and contained very little fat $(0.9 / 100 \mathrm{~g})$, and fibre $(28.3 \mathrm{~g} / 100 \mathrm{~g})$ (Onyechi et al., 2007). The physicochemical properties showed that mean particle size, WBC and viscosity values were 115.0, 5.85 and $5.5 \mathrm{dl} / \mathrm{g}$ respectively. Soluble NSP was $15.5 / 100 \mathrm{~g}$ and the starch content was $45.3 \mathrm{~g} / 100 \mathrm{~g}$, the sugar composition of the SNSP showed high levels of arabinose $(8.0 \mathrm{~g} / 100 \mathrm{~g})$, glalactose (2.2 $\mathrm{g} / 100 \mathrm{~g})$ and uronic acid $(4.2 \mathrm{~g} / 100 \mathrm{~g})$ (Onyechi et al., 2007).

The processing of CR flour and the preparation of the traditional soups is tedious and time consuming. For these reasons the use of CR flour is on the decline and the consumption of $C R$ vegetable soup is on the decrease in most urban areas of Nigeria. The scarcity, non-compliance and high cost of diabetic drugs in Nigeria makes this study of vital importance. It was therefore important to explore dietary treatment of NIDDM using potential indigenous foods.

The purpose of this work was to determine the effects of $\mathrm{CR}$ on the lipid profile of rats, as screening model. This study also evaluated the effect of CR flour on the postprandial glucose and insulin levels in humans. This work also aimed at finding a suitable food base to incorporate $\mathrm{CR}$ flour that will be acceptable to diabetics in urban areas in Nigeria. The result of this work will determine the possibility of using CR in the prevention, management and treatment of NIDDM, as well as diversify and increase the consumption of CR flour.

\section{MATERIALS AND METHODS}

\section{Metabolic study}

\section{Rat study}

Preparation of rat diets: Two diets were used in the rat experiment, the control diet (CD) and CR diet (CRD). Five kilogram of $\mathrm{CD}$ was formulated using casein (New Zealand milk products 
mix); mineral mix, vitamin mix (King's College mix), sucrose (Booker Fitch Food services), solka floc (Johnsen Jordensen and Wettre Ltd) and corn starch (Cerestar, Manchester HHIPA). These ingredients were blended together in a Hobart mixer for 15 min. Corn oil was heated to $80^{\circ} \mathrm{C}$ and the calculated amount of cholesterol (BDH chemicals Ltd) was weighed and stirred into the corn oil and mixed well to dissolve. The mixture of corn oil and cholesterol was added to the dry ingredient of casein, mineral mix, vitamin mix, sucrose, solka floc and corn starch and blended for 30 min until well distributed. The mixture was passed through a 1/8 inch mesh sieve. Homogenization of the mixture was assured by mixing for a further $30 \mathrm{~min}$ in the Hobart mixer. The diet was stored at $-20^{\circ} \mathrm{C}$ in self-sealed freezer bags until required for the experiment.

The test diet was prepared to contain Cissus flour. The amount of CR flour containing $10 \mathrm{~g}$ dietary fibre was determined from the results of preliminary analysis of $\mathrm{CR}$ and the calculated quantity of CR flour was added to the CD. The test diet provided approximately $10 \mathrm{~g}$ total fibre per $100 \mathrm{~g}$ diet while maintaining similar protein and fat levels like the CD. The amount of casein and corn oil in the test diet was adjusted to maintain similar protein and fat contents with the CD. Thus, the Cissus flour replaced some of the protein, fat and starch in the test diet. Enough corn starch was used to make up a batch size of $5 \mathrm{~kg}$ diet.

Feeding of the rats: Twenty male Sprague-Dawley rats, supplied by A. Juck \& Sons, London were used for the animal study. The rats that weighed between 71 to $87 \mathrm{~g}$ on arrival, were placed in a cage and fed stock diet for 2 days and ground stock diet for five days prior to the experimental period in order to acclimatize rat to eating ground diet. After one week of acclimatization, the rats were assigned into the two groups with a mean weight of 115 to $115 \mathrm{~g}$ so that rat from each litter went into an experimental group. The group of rats was therefore assumed to be genetically similar. The rats were housed individually in cages with trays and filter paper to collect spill and faeces. The rats' food intake was recorded by providing each rat with an individual weighed pot of food and the food pots were weighed on alternate days before toping up food supply and reweighing. At the end of the experiment the rats were anaesthetized and bled from the heart using heparinized needle and syringe to prevent clotting. The blood was collected and centrifuged at $2,500 \mathrm{rpm}$ for $15 \mathrm{~min}$ before the plasma was separated from the cells, stored in LP3 tube at $-20^{\circ} \mathrm{C}$ until analysis.

The plasma cholesterol was determined by enzymatic method (Trinder, 1960; Roschkau et al., 1975; Siedel et al., 1981) supplied by Boehringer - Mannheim (Boehringer CHOD/PAP kit method). The principal is based on the hydrolysis of cholesterol ester to free cholesterol and fatty acids by cholesterol ester hydrolase. Free cholesterol is oxidized by reacting with oxygen in the presence of cholesterol oxidase and hydrogen peroxide is formed which reacts with a chromophore to produce a pink colour The absorbance of the resulting solution was read in a spectrophotometer (UV/VIS spectrophotometer, Philip instrument, UK), against a blank at $500 \mathrm{~nm}$. The plasma triglyceride of the rats was analyzed using the enzymatic method described by Tiffany et al., 1974. The Boehringer Mannheim kit method was used for this analysis and absorbance of the sample was read against a blank at $500 \mathrm{~nm}$ wavelength in a spectrophotometer.

\section{Human study}

Preparation of the experimental bread: The bread rolls were prepared using the Chorleywood bread process (Apling and Ellis, 1982). The brown wheat flour used was Ploughman's brown flour (Sovereign, Allied Mills, London EC3R 7PE). The hydrogenated vegetable fat was the flora brand (Unilever, UK). Each batch of bread dough contained variable amounts of water depending on the viscosity of the flour. The CR flour was incorporated into the bread as a replacement for wheat flour. The weight of dough used was calculated such that a total of $50 \mathrm{~g} \mathrm{CHO}$ was contained in two bread rolls. Thus the $\mathrm{CHO}$ content of the flour and the other added foodstuff were considered in arriving at the total $\mathrm{CHO}$ content of the bread.

Feeding of the subjects: Ten healthy non-diabetic subjects visited the metabolic lab twice a week after an overnight fast. The subjects were fed a control bread meal (CBM) made with only wheat flour and an experimental bread made from CR flour. The meals consisted of two small bread rolls, $38 \mathrm{~g}$ apricot jam (Robinson's) and sufficient water to make a total meal weight of $400 \mathrm{~g}$. The available carbohydrate portion of the meal was $75 \mathrm{~g}$, the bread rolls supplied $50 \mathrm{~g} \mathrm{CHO}$ mostly in the form of starch and the jam provided $25 \mathrm{~g}$ of available $\mathrm{CHO}$ mostly as sucrose making a total of $75 \mathrm{~g}$ of available $\mathrm{CHO}$. The CRB contained $5 \mathrm{~g}$ of SNSP as calculated from by Englyst et al. (1992); analysis of the foods plus additional SNSP from the wheat flour. At the start of the meal a fasting venous blood sample of $10 \mathrm{ml}$ was taken from each subject using EDTA extainers. The breakfast meal was eaten within a 15 min period. Postprandial blood samples were taken at 30,60, 120 and 150 min from the commencement of the meal. The study was approved by King's College ethical committee.

\section{Analysis of blood glucose and insulin levels}

Blood glucose level was measured by the glucose oxidase test using Boehringer Mannheim diagnostic kit. Blood glucose concentration was determined after deproteinisation of the blood sample. The quantitative determination of human insulin in-vitro was done using Boehringer Mannheim diagnostic kit based on enzyme immunological reactions. The ES 22 combi step 22 program, B auto machine was used for the analysis.

\section{Statistical analysis}

The difference between the effect of the diets on the rats was determined using analysis of variance, ANOVA, Statistical Analysis System package, SAS Institute (1985). The level of significance was at $p<0.05$. The difference between the effect of the experimental meals on the blood glucose and insulin incremental values were determined by repeated measures ANOVA with statistical package (Statistical Analysis System package, SAS Institute (1985). Integrated glucose and insulin increments were estimated by calculation of area under the curve (AUC; trapezoid rule).

\section{RESULTS}

\section{Rat study}

Table 1 gives a description of the composition of the control diet and experimental diet which was essentially the same expect the addition of the experimental food CR flour. In Table 2 the result of the nutrient analysis of the rats diet is shown. The nutrients were comparable expect for the fibre in the CRD, which is due to the additional fibre from the CR flour.

Table 3 shows the effect of CD and CRD diets on the fasting plasma cholesterol and triglyceride levels $(\mathrm{mmol} / \mathrm{L})$ of rats. The result showed that mean plasma cholesterol levels of rats fed CRD was significantly lower 
Table 1. Composition of control diet (CD) and diet containing CR (CRD) fed rats.

\begin{tabular}{lcc}
\hline \multirow{2}{*}{ Ingredients } & \multicolumn{2}{c}{ Quantity of ingredients (g/1000 $\mathbf{~})$ diet } \\
\cline { 2 - 3 } & CD & CRD \\
\hline Casein & 150 & 133 \\
Fat (corn oil) & 100 & 100 \\
Vitamins & 20 & 20 \\
Minerals & 40 & 40 \\
Sucrose & 100 & 100 \\
Cholesterol & 10 & 10 \\
Solka floc & 50 & 50 \\
Food samples & - & 354 \\
Corn starch & 530 & 193 \\
\hline
\end{tabular}

Table 2. Nutrient analysis of the control diet (CD) and diet containing CR (CRD) fed to rats.

\begin{tabular}{lcc}
\hline Nutrients & CD & CRD \\
\hline Moisture (\%) & 6.11 & 5.89 \\
Fat (\%) & 10.00 & 10.1 \\
Protein (\%) & 15 & 15 \\
Ash (\%) & 4.8 & 5.1 \\
Available CHO (\%) & 58.0 & 45.0 \\
Fibre by difference (\%) & 6.1 & 19.0 \\
Total CHO & 64.1 & 63.6 \\
& 406.0 & 404.0 \\
\hline
\end{tabular}

Table 3. Fasting plasma cholesterol and triglyceride levels mean $(\mathrm{mmo} / \mathrm{L})$ of rats fed control diet (CD) and CR test diet (CRD).

\begin{tabular}{lcc}
\hline Diet & Plasma cholesterol level (mmol/L) & Plasma triglyceride levels (mmol/L) \\
\hline CD & $3.97 \pm 0.17^{\mathrm{a}}$ & $0.80 \pm 0.07^{\mathrm{a}}$ \\
$\mathrm{CRD}$ & $3.32 \pm 0.09^{\mathrm{a}}$ & $0.63 \pm 0.11^{\mathrm{b}}$ \\
\hline
\end{tabular}

Values are mean \pm sem. $(n=10)$; Column values with same superscript are significantly different from each other at $p<0.05$.

than those fed the CD at $p<0.05$. The result of the plasma triglyceride levels of rats fed the CD and CRD showed no significant reduction. However CRD showed a lowering effect.

\section{Human study}

In Table 4 the food ingredients used for the production of the $\mathrm{CB}$ and $\mathrm{CRB}$ were shown and the nutrient composition of the meals were shown in Table 5. Figure 1 shows the effect of the bread meals on the incremental blood glucose levels. The comparison of the mean incremental glucose rise after the consumption of $\mathrm{CB}$ with the CRB showed that there was no significant difference but there was apparent decrease. The difference between the bread meals was analysed at the time intervals, the CRB showed a significant difference at 150 min. The effect of the bread meals on the incremental insulin levels is shown in Figure 2. Comparison of the mean incremental insulin rise after the consumption of the $C B$ and $C R B$ showed no significant difference between the two bread meals, however there was apparent reduction with CRB. The difference between the bread meals was analysed at the time intervals, the CRB showed a significant difference at $90 \mathrm{~min}$. A significant reduction $(p<0.005)$ was found in the area under the curves (AUC) of CRB compared to the CB. 
Table 4. Food ingredients used for the preparation of control bread (CB) and test bread containing CR (CRB).

\begin{tabular}{lcc}
\hline \multirow{2}{*}{ Ingredient } & Quantity of ingredients & (g/1000 $\mathbf{~ g}$ flour) \\
\cline { 2 - 3 } & CB & CRB \\
\hline Brown flour & 1000 & 550 \\
Salt & 18 & 18 \\
Experimental foods & - & $450^{*}$ \\
Fat(hydrogenated) & 7 & 7 \\
Improver & 100 & 100 \\
Fresh yeast & 25 & 25 \\
Water & 675 & 750 \\
\hline
\end{tabular}

*Equivalent to $63 \mathrm{~g}$ soluble fibre (Englyst analysis).

Table 5. Nutrient composition of bread meals fed human non-diabetic adults $(n=10)$.

\begin{tabular}{lccccc}
\hline Type of bread & Amount $(\mathbf{g})$ & Protein $\mathbf{( g )}$ & Fat $\mathbf{( g )}$ & Available CHO $\mathbf{( g )}$ & Total SNSP \\
\hline Control bread & 136 & 10.2 & 1.9 & 70.0 & 1.8 \\
Cissus bread & 148 & 7.9 & 1.7 & 70.1 & 6.1 \\
\hline
\end{tabular}

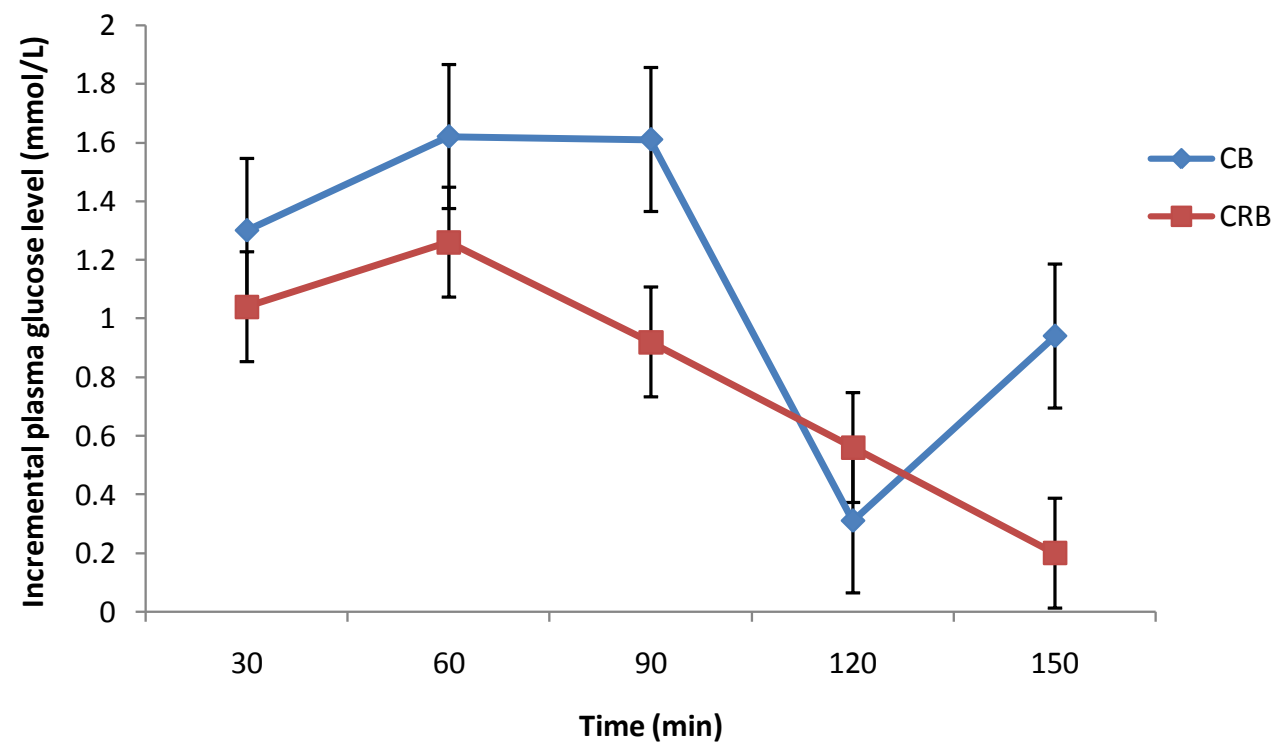

Figure 1. Mean incremental plasma glucose levels $(\mathrm{mmol} / \mathrm{L})$ of healthy subjects fed control bread and CRB. $\mathrm{n}=10$.

\section{DISCUSSION}

The animal study showed a significant decrease $(p<0.05)$ in the plasma cholesterol level of rats fed the CRD compared to the CD as shown in Table 3. However there was no significant reduction in the plasma triglyceride levels of rats fed CRD compared to the CD but there was apparent reduction with CRD (Table 3). The result of the human study shows that CRB elicited a significant reduction $(p<0.5)$ on plasma glucose (Figure 1) and insulin (Figuere 2) at 150 and $90 \mathrm{~min}$, respectively. A significant reduction $(p<0.005)$ was found in the area under the curves (AUC) for glucose and insulin with the consumption of CRB compared to the CB. C. rotundifolia is the stem of a shrub and limited research work has been done to examine such materials as CR. A material which may be similar to $C R$ is konjac mannan, which is prepared from fresh roots and has shown to reduce 


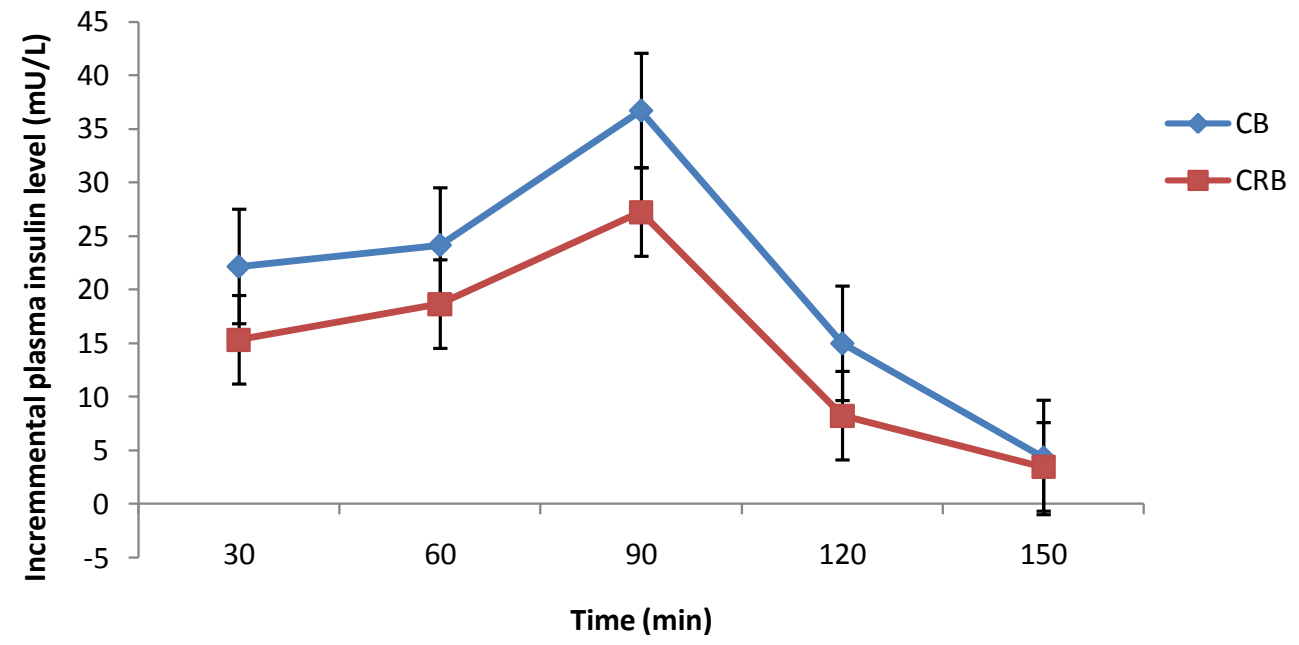

Figure 2. Mean incremental plasma insulin levels ( $\mathrm{mU} / \mathrm{L}$ ) of subjects fed control bread and CRB. $\mathrm{n}=10$.

postprandial plasma glucose and insulin concentration in humans (Ebihara et al., 1981). These authors indicated that beneficial effects of konjac mannan which contain viscous soluble NSP just as CR, were related to delayed stomach emptying, modified responses in gastrointestinal hormones and delayed glucose diffusion. Delayed gastric emptying was a major factor in reducing plasma glucose and insulin concentration as well as decreased intraluminal glucose diffusion (Brownlee, 2011). CR has some similarity with konjac mannan, both contain soluble NSP, although one is described as a root and the other a stem, they are both "woody" parts of plants which contain viscous soluble NSP. The result of this study shows that $\mathrm{CR}$ flour has the same physiological effect on human and animals just as konjac mannan due to the similarity their physico-chemical properties (Nichenametla et al., 2014).

CR had a viscosity of $5.5 \mathrm{dl} / \mathrm{g}$, and a SNSP content of $14.6 \mathrm{~g} / 100 \mathrm{~g}$ (Onyechi et al., 2007). Jenkins et al. (1978) showed a positive correlation between mean peak rise in blood glucose and gum viscosity of a wide variety of viscous NSPs. The authors postulated that the action of these viscous materials maybe two fold, delay in gastric emptying and delay in glucose absorption from the small intestine. Viscous gels like CR entrap glucose and slowly release it for absorption. This effect can explain the reduction in the postprandial blood glucose concentration in humans fed CRB.

The effect of CRD on the lipid profile of experimental rats is attributable to increased fecal bile acid excretion. Cummings (1981) indicated that the loss of these cholesterol containing compounds has hypocholesterolemic effects. Studies have shown that SNSP are almost completely fermented by colonic bacteria to produce short chain fatty acids (SCFA) like acetate, propionate and butyrate (Cummings, 1981). Chen et al. (1984) in their study with rats showed that dietary propionate lowered serum and liver cholesterol. The authors suggested that this reduction is due to propionate inhibiting hepatic cholesterol synthesis. This same mechanism is attributable in the rats fed CRD since CR flour contain SNSP hence the decrease in cholesterol levels in the rats. It is also possible that $\mathrm{CR}$ which is high in starch produce SCFA from both the SNSP and the starch, indicating a high level of propionic acid with hypocholesterolemic effect (Chen et al., 1984; Brownlee, 2011).

Water binding capacity (WBC) is the maximum amount of water that can be taken up per unit weight of dry food material in the presence of excess water. It is the ability of fibre to hold water under specific conditions. Onyechi et al. (2007) showed that CR flour had a WBC of 5.58. Studies have also shown that NSPs like CR with high WBC prolong gastric emptying (Bueno et al., 1981) hence decreased postprandial blood glucose levels in human.

CR has a mean particle size of $115 \mu \mathrm{m}$ (Onyechi et al., 2007). It has been shown that particle size or the texture of food plays an important role in glycaemic response. Food of coarse consistency produced smaller glycaemic responses than finely milled food grains which break the cell walls, producing a quicker access of amylase to the starch flour (O'Dea et al., 1980). Particle size is property of dietary fibre that helps in modulating the postprandial blood glucose level. This particular property is attributable to CR flour; hence the positive result obtained in the postprandial glucose and insulin levels in the human study and the reduction in the lipid profile of rats.

CR flour contained a high level of starch $(45.3 \mathrm{~g} / 100 \mathrm{~g})$ (Onyechi et al., 2007). Studies have shown a reasonable correlation between glycaemic index, and in vitro digestibility of starchy foods (Holm et al., 1988; Dhingra et al., 2011; Brownlee, 2011; Bodinham et al., 2014). 
Crapo et al. (1971) showed that the glycaemic and insulin response in humans were not only related to the dietary fibre content of the foods but also to the difference in the digestibility of different starches (Coulston et al., 1980; Jenkins et al., 2002, Allen et al., 2011). Goddard et al. (1984) showed that amylose/amylopectin ratio is a contributory factor to low glycaemic index. Foods that are known to have high levels of amylose in their starch granules are more slowly digested compared to carbohydrate foods that contain less amylose and more amylopectin (Goddard et al., 1984; Benhall et al., 2006). This is due to the fact that amylopectin has larger surface area per molecule than amylose. In addition amylose unit are more bound to each other by hydrogen bonds making them less available for amylolitic attack (Schooch and Maywald, 1976). However, the structure of the starch in CR flour has not been studied so the amylose/amylopectin ratio is not known. However, CR starch has attributes that makes it resistant to digestion, as indicated in the postprandial glucose and insulin human subjects and decreased plasma lipids in the rat study result (Bodinham et al., 2014).

\section{Conclusion}

All the attributes of $\mathrm{CR}$ flour is indicative that it has biologically active properties which are beneficial in the therapeutic management of non-insulin dependent diabetes mellitus (NIDDM). The dietary management and prevention of diabetes using locally available food sources is of paramount importance in Nigeria because of the high prevalence rate of diabetes (Thiam et al., 2006), the medical resources for diabetic care are either, scarce, unavailable and often unaffordable. The high cost of materials for diabetic care is unprecedented due to the worsening economic condition in Nigeria. This is disastrous with a disease like diabetes where the underlying condition is incurable and lifelong treatment and care is necessary. CR is locally available, cheap, natural food with great potential as a useful adjunct in the dietary management of NIDDM.

\section{Conflict of Interests}

The author(s) did not declare any conflict of interests.

\section{REFERENCES}

Allen EJG, Abets I, Astrup A, Martinez JA, Van Baak MA (2011). Starches, sugars and obesity. Nutrient 3(3):341-369.

Apling EC, Ellis PR (1982). Guar bread: concept to application. Chemistry and Industry. London. pp. 950-954.

Benhall KM, Scholfield DJ, Hallfrish JG, Liljeberg-Elmstahl (2006). Consumption of both resistant starch and $\beta$-Glucan improves postprandial Glucose and insulin in women. Diabet. Care 29(5):976981.

Bodinham CL, Smith L, Thomas EL, Bell JR, Costabile A, Rossel-Jones
D, Mumpleby AM, Robertson MD (2014). Efficacy of increased resistant starch consumption in human Type 2 diabetes. Endocr. Connect. 3(2):75-84.

Braaten JT, Scott FW, Wood PJ, Reidel KD, Poste LM, Collins MW (1994). High $\beta$-glucan oat bran and oat gum reduce postprandial blood glucose and insulin in subjects with and without type 2 diabeteis. Diabet. Med. 11:312-318.

Brownlee IA (2011). The physiological roles of dietary fibre. Food Hydrocoll. 25(2):238-250.

Bueno L, Praddante F, Fioramonti J, Ruckebusch Y (1981). Effect of dietary fibre on gastrointestinal motility and jejuna transit time in dogs. Gastronterology 80:701-707.

Burkitt DP, Trowell HC (1976). Refined carbohydrates and diseases, some implications of dietary fibre. London, UK: Academic press Inc.

Chen WJL, Anderson JW, Jenkins D (1984). Propionate may mediate the hypocholesterolemic effects of certain soluble plant fibres in cholesterol fed rats. Proc. Soc. Exp. Biol. Med. 175:215-218.

Coulston A, Greenfield M, Kramer F, Tokey T, Reaven G (1980). Effect of source of dietary carbohydrate on plasma glucose and insulin responses to test meals in normal subjects. Am. J. Clin. Nutr. 33:1279-1282.

Crapo P, Reaven G, Olefsky J (1971). Post-prandial plasma glucose and insulin responses to different complex carbohydrates. Diabetes 26:117-183.

Cummings JH (1981). Dietary fibre. Br. Med. Bull. 37:65-70.

Dhingra D, Micheal M, Rajput H, Patil RT (2012). Dietary fibre in foods: a review. J. Food Sci. Technol. 49(3):255-266.

Dreher ML (1987). Handbook of dietary fibre. O.R Fennema, G.W. Sanderson, P. Walstmara, M. Karel, S.R. Tannenboum, J.R. Whitaker eds. New York: Marcel Dekker Inc.

Ebihara K, Masuhara R, Kiriyama S (1981). Major determinants of plasma-flattening activity of a water-soluble dietary fibre: effect of konjac mannan on gastric emptying and intraluminal glucosediffusion. Nutr. Rep. Int. 23:1145-1156.

Edward CA, Johnson IT, Read NW (1988). Do viscous polysaccharides slow absorption by inhibiting diffusion or convection? Eur. J. Clin. Nutr. 42:307-312.

Ellis PR, Rayment P, Wang Q (1996). A physico-chemical perspective of plant polysaccharides in relation to glucose absorption, insulin secretion and the entero-insular axis. Proc. Nutr Soc. 55:881-898.

Englyst HN, Quigley ME, Hudson GJ, Cumming JH (1992). Determination of dietary fibre as non-starch polysaccharide by gas liquid chromatography. Analyst 177:1707-1714.

Fairchild RM, Ellis PR, Byrne AJ, Luzio SD, Mir MA (1996). A new breakfast cereal containing guar gum reduces postprandial plasma glucose and insulin in normal weight human subjects. Br. J. Nutr. 76:63-73.

Food Agricultural Organization (FAO) (1988). Traditional food plants A source book for promoting the exploitation and consumption of plant foods in Arid semi-Arid and semi-humid lands of Eastern Africa. Rome: FAO. pp. 234-245.

Fujii $\mathrm{H}$, Iwase M, Ohkum T, Ogata-Kaizu S, Ide H, Kikuchi Y, Idewald Y, Joudal T, Hira Kawa Y, Uchida K, Sasaki S, Nakamura U, Kitazono T (2013). Impact of dietary fiber intake on glycemic control, cardiovascular risk factor and chronic disease in Japanese patients with type 2 diabetes mellitus: the Fukuoka diabetes registry. Nutr. J. 12:159.

Goddard MS Young G, Marcus R (1984). The effect of amylase content on insulin and glucose responses to ingested rice. Am. J. Clin. Nutr. 39:388-392.

Guariguata L, Whiting DR, Hambleton I, Beagley J, Linnenkamp U, Shaw J. (2014). Global estimates of diabetes prevalence for 2013 and projections for 2035. Diabetes Res. Clin. Prac. 103(27):137-149.

Hall V, Thomsen RW, Henriksen O, Louse N (2011). Diabetes sub Saharan Africa 1999-2011 epidemiology and public health implication, a systematic review. BMC Public Health 11:564.

Holm J, Lunquist I, Bjorock I, Eliasson AC, Asp NG (1988). Degrees of starch gelatinisation, digestion rate of starch in vitro and metabolic response in rats. Am. J. Clin. Nutr. 17:1010-1016.

Jacobs DR (2015). Nutrition: The whole cereal grain is more informative than cereal fibre. Nat. Rev. Endocrinol. 11:389-390.

Jenkins JA, Kendall CWC, Augustin LSA, Franceschi S, Hamidi M, 
Marchie A, Jenkins AL, Axeisen (2002). Glycemic index: Over view of complications in health and disease. Am. J. Clin Nutr. 76(1):26652735.

Jenkins DTA, Wolever TMS, Leeds AR, Gassull AM, Haisman P, Dilawari lberti J, Goff, DV, Metz, GL, Alberti (1978). Dietary fibre, fibre analogues and glucose tolerance: Importance of viscosity. $\mathrm{Br}$. Med. J. 279:1392-1394.

Johnansen HN, Bach Knundsen KE, Sandström B, Skjøth F (1990). Effect of varying content of soluble dietary fibre from wheat flour and oat milling fractions on gastric emptying in pigs. Br. J. Nutr. 75:339351.

Kaczmarczyk M, Miller MJ, Freund GS (2012). The health benefits of dietary fibre: Beyond the usual suspects of type 2 diabetes mellitus, cardiovascular disease and colon cancer. Metabolism 61(8):10581068.

Ley SH, Hamdy O, Mohan V, Hu FB (2014). Prevention and management of type 2 diabetes: dietary components and nutritional strategies. Lancet 383(9933):1999-2007.

Nichenametla SN, Weidauer LA, Wey HE, Tianna MB, Specker BL, Dey M (2014). Resistant starch type 4-enriched diet lowered blood cholesterols and improved body composition in a double blind controlled cross-over intervention. Mol. Nutr. Food Res. 58(6):13651369.

O'Dea K, Nestel P, Analoff L (1980). Physical factors influencing postprandial glucose and insulin responses to starch. Am. J. Clin. Nutr. 33:760-765.

Onyechi UA, Judd PA, Ellis PR (2007). The processing and nutrient analysis of some unexploited Nigerian plant foods. West Afr. J. Foods Nutr. 8(1):35-44

Oputa RN, Chinyere S (2012). Diabetes mellitus: a global epidemic with potential solutions. Afr. J. Diabet. Med. 2(2):33-35.

Ram A, Mary S, Yamuna A, Murugesan N, Snehalatha C (2008). High prevalence of diabetes and cardiovascular risk factors associated with urbanization in India. Diabet. Care 31(5):893-898.

Ram A, Snehalatha C, Zimmet B, Thomas K (2004). Global prevalence Diabetes. Diabet. Care 27(5):1047-1053.

Ramachandran A, Snehalatha C, SamithA, Nanditha (2012). Trends in Prevalence of diabetes in Asian countries. World J. Diabetes 3(6):110-117.

Ramachandran A, Snehalatha C, Zimmet P, King H, Taylor Raper LR, Baikau B, Borger J, Heriot W, Thoma K (2004). The high prevalence of diabetes mellitus, impaired glucose. Diabet. Care 27(9):1047-1053.
Riccardi G, Rivellese AA, Rosalba G (2008). Role of glycemic index and glycemic load in prediabetes and diabetes. Am. J. Clin. Nutr. 89(1):2695-2745.

Roschkau P, Bernt E, Cruber W (1975). Methods in Enzymatic Analysis, $2^{\text {nd }}$ ed HN Englyst editor. New York: Academic Press Inc.

Schooch TJ, Maywald EC (1976). Preparation and properties of various legume starches. Cereal Chem. 45:564-573.

Siedel JH, Schlumberger H, Klose S, Ziegenhorn J, Wahlefeld IW (1981). Improved reagent for the enzymatic determination of serum cholesterol. J. Clin. Biochem. 19:838-839.

Slyper AH (2013). The influence of carbohydrate quality on cardiovascular disease, the metabolic syndrome, Type 2 diabetes and obesity and obesity an overview. J. Pediatr. Endocrinol. Metab. 26(7-8):617-629.

Statistical Analysis System Package (1985). SAS User's Guide statistics, $5^{\text {th }}$ ed. North Carolina USA. SAS Inst. Inc.

Thiam I, Samba K, Lwanga D (2006). Double burden of malnutrition and diet related chronic diseases in the West Africa. Standing Committee on Nutrition 33:3.

Tiffany TO, Morton JM, Hall EM, Garrte AS (1974). Clinical evaluation of kinetic enzymic fixed time and integral analysis of serum triglycerides Clin Chem. 20:476-481.

Trinder P (1960). Determination of glucose in blood using glucose oxidase with an alternative oxygen receptor. Ann. Clin. Biochem. 6:24-27.

Trowell HC (1975). Dietary fibre hypothesis of the etiology of diabetes mellitus. Diabetes 24(8):762-765.

Trowell H, Southgate DAT, Wolever TMS, Leeds AR, Gassull MA, Jenkins DAT (1976). Dietary fibre redefined. Lancet 1:967.

Uduaghan E (2002). 1 million Nigerians are blind. Scientific Conference/Annual General Meeting of the Diabetes Association of Nigeria. Lagos Nigeria, $6^{\text {th }}$ Nov, 2002.

World Health Organization (2000). Preventing and managing the global epidemic: A report of a World Health Organization Consultation on obesity.

World Health Organization/Food Agriculture Organization (WHO/FAO) (2003). Diet, Nutrition and the prevention of chronic Disease. A report of a joint WHO/FAO expert consultation, Geneva, 2003; 28 January-1 February. 